\title{
Canadian Expert Panel recommendations on the management of CNS symptoms related to efavirenz
}

\author{
M John Gill MB ChB MSc FRCPC ${ }^{1}$, Anita Rachlis MD MEd FRCPC ${ }^{2}$, Sharon Walmsley MSc MD FRCPC ${ }^{3}$, \\ Mark Halman MD FRCPC ${ }^{4}$ and the Efavirenz Consensus Working Group
}

MJ Gill, A Rachlis, S Walmsley, M Halman and the Efavirenz Consensus Working Group. Canadian Expert Panel recommendations on the management of CNS symptoms related to efavirenz. Can J Infect Dis $2001 ; 12($ Suppl C):20C-30C.

Efavirenz is a potent antiretroviral agent used in combination with other antiretroviral agents as part of highly active antiretroviral therapy. Efavirenz is generally well tolerated because the majority of its adverse effects are self-limiting, with central nervous symptoms and rash being the most frequent. In routine practice, the discontinuation rate of efavirenz due to adverse effects appears higher than that described in clinical trials. To minimize early treatment interruption and maximize the benefit of long term viral suppression that can be achieved with efavirenz therapy, health care providers and patients have identified that there is a need for information, education about and practical tools for the management of efavirenz-related side effects. To this end, a panel of experts in the care of HIV patients consisting of primary care physicians, infectious disease specialists, psychiatrists and pharmacists was convened. Through the evaluation of current literature and discussion among the group, the panel arrived at consensus recommendations. The present report outlines general management recommendations that apply to adverse effects related to efavirenz initiation, as well as specific management strategies for central nervous system symptoms such as agitation, sleep disturbances, dreams, dizziness, impaired concentration and depression. It is hoped that these practical recommendations will aid clinicians in minimizing and improving patient tolerance of side effects, thereby achieving improved adherence and patient outcomes.

Key Words: Adverse effects; Central nervous system symptoms; Efavirenz

Pour le résumé, voir page suivante

\footnotetext{
${ }^{1}$ Southern Alberta Clinic and Department of Medicine, University of Calgary, Calgary, Alberta; ${ }^{2}$ Division of Infectious Diseases, Department of Medicine, Sunnybrook and Women's College Health Sciences Centre, University of Toronto; ${ }^{3}$ Department of Medicine, University of Toronto; ${ }^{4}$ HIV Psychiatry Program and Medical Psychiatry Consultation Service, St Michael's Hospital, Department of Psychiatry, University of Toronto, Toronto, Ontario

Correspondence: Dr M John Gill, South Alberta Clinic, \#213, 906-8th Avenue SW, Calgary, Alberta T2N 1H9. Telephone 403-234-2399, fax 403-262-4893, e-mail john.gill@calgaryhealthregion.ca
} 


\section{Recommandations du Groupe d'experts canadiens sur le traitement des symptômes du SNC, liés à l'efavirenz}

RÉSUMÉ : L'efavirenz est un antirétroviral puissant, utilisé en association avec d'autres agents antirétroviraux dans le cadre de la multithérapie. L'efavirenz est généralement bien toléré; en effet, la plupart de ses effets indésirables, se manifestant sous forme d'éruptions cutanées ou de symptômes du système nerveux central, sont spontanément résolutifs. Toutefois, l'interruption du médicament attribuable aux effets indésirables semble, en pratique, plus fréquente que celle relevée dans les essais cliniques. Afin de réduire au minimum les interruptions précoces de traitement et de tirer le maximum de bienfaits liés à la suppression virale prolongée, des fournisseurs de soins et des patients ont dégagé trois besoins en ce qui concerne le traitement des effets indésirables, secondaires à la prise d'efavirenz, soit l'information, l'éducation et la conception d'outils pratiques. Un groupe d'experts dans la prestation de soins aux patients porteurs du VIH a donc été formé à cette fin; il se composait de médecins de premier recours, d'infectiologues, de psychiatres et de pharmaciens. Le groupe, après avoir évalué la documentation actuelle et tenu des discussions, en est arrivé à des recommandations consensuelles. Le présent rapport expose les principales recommandations relatives au traitement des effets indésirables, liés à la prise initiale d'efavirenz, ainsi que des stratégies particulières visant à soulager les symptômes du système nerveux central comme l'agitation, les troubles du sommeil, les rêves, les étourdissements, les difficultés de concentration et la dépression. Aussi le groupe espère-t-il que ces recommandations pratiques aideront les cliniciens à réduire les effets indésirables et à accroître la tolérance des patients, d'où meilleure observance thérapeutique et meilleurs résultats cliniques.

$\mathrm{E}$ favirenz is a potent antiretroviral agent that is used in combination with other agents as part of highly active antiretroviral therapy (HAART) against HIV. Efavirenz is the only non-nucleoside reverse transcriptase inhibitor listed among the first-line agents recommended in the United States Department of Health and Human Services guidelines (1). It is effective in a once-a-day dosing and may be taken without regard to food. This provides for a simple regimen that enhances patient adherence.

Efavirenz is relatively well tolerated. The most commonly reported adverse effects (AEs) are rash and central nervous system (CNS) symptoms such as dizziness, insomnia, somnolence, impaired concentration, vivid dreams, nightmares, depression and agitation. These AEs are usually self-limiting $(2,3)$. A rash may occur in approximately $26 \%$ of patients within the first two weeks of initiating efavirenz, but in most patients, this rash is mild to moderate and resolves within one month of continued therapy with or without antihistamine use. In clinical trials, $1.7 \%$ of the participants discontinued drug therapy as a result of rash. Approximately $50 \%$ of the patients report some form of CNS symptoms on initiation of efavirenz; however, these generally resolve within the first two to four weeks of therapy. In clinical trials, only $2.1 \%$ of patients discontinued therapy as a result of CNS symptoms.

In routine practice, the discontinuation rate of efavirenz due to AEs appears to be higher than that in clinical trials. The procedures for care delivery and availability of patient support may be significantly different in clinical trials compared with routine practice. The reported discontinuation rates also vary between clinics across Canada (4). This may reflect differences in both clinical practice and the population served. Some variations also exist in support programs, drug counselling, monitoring and documenting of AEs, as well as individual physicians' comfort level or persistence in the management of efavirenz-related CNS symptoms. Needs assessment surveys among health professionals and patient groups such as AIDS service organizations revealed that there is a need for information, education and practical tools to manage the treatment-associated symptoms of efavirenz (4).

To this effect, a panel of experts in the care of HIV patients consisting of primary care physicians, infectious disease specialists, psychiatrists and pharmacists was convened to discuss and develop consensus recommendations on the best practice management of efavirenz-related AEs. The goal of this expert panel was to review available information and develop practical guidelines for the management of the CNS effects of efavirenz, so as to minimize early treatment interruptions and maximize the benefit of long term viral suppression.

\section{METHODS}

The following key topics in the management of efavirenzrelated AEs were identified.

- General management strategies for any efavirenz-associated AE: Patient education can be critical for successful therapy. The role and content of patient education regarding potential adverse events to be used before therapy initiation and while on antiretroviral therapy are included in this section.

- Management recommendations for specific CNS symptoms associated with efavirenz: Specific CNS symptoms discussed are agitation, sleep disturbances, dreams, dizziness, impaired concentration and depression. 
TABLE 1

Strategies to improve adherence of antiretroviral therapy

Medication-related

- Inform, anticipate and treat side effects.

- Simplify food requirements.

- Avoid adverse drug interactions.

- If possible, reduce dose frequency and number of pills.

Patient-related

- Negotiate a treatment plan that the patient understands and to which he or she commits.

- Take time and have multiple encounters to educate and explain the goals of therapy and need for adherence.

- Establish readiness to take medication before the first prescription is written.

- Recruit family and friends to support the treatment plan and need for adherence.

- Develop a concrete plan for the specific regimen, including relation to meals, daily schedule and possible side effects.

- Consider pill trials with jelly beans.

- Provide written schedule of medications, daily or weekly pill boxes, alarm clocks or other devices.

- Develop adherence support groups or add adherence to the regular agenda of support groups.

- Develop linkages with community organization around adherence with educational sessions and practical strategies.

Physician-related

- Establish trust.

- Serve as educator and source of information, ongoing support and monitoring.

- Provide access between visits for questions, problems via pager and holiday coverage.

- Monitor ongoing adherence and intensify management in periods of low adherence, such as suggesting more frequent visits and recruitment of family, friends and health care team members.

- Use health care team for difficult patients and patients with special need, such as peer educators for injection drug users or adolescents.

- Consider impact of new diagnoses on adherence, particularly depression and drug use.

Health team-related

- Use nurses, pharmacists, peer educators, volunteers and drug counsellors to reinforce adherence.

- Provide training related to adherence to support team.

- Add adherence interventions to job description of support team members.

Data from reference 1

Individual panellists provided recommendations for each of the topics identified using existing evidence; after, small groups of panellists consolidated each set of recommendations for review by the full panel. The panel then arrived at a consensus through extensive discussion.

\section{RECOMMENDATIONS}

Successful antiretroviral therapy requires a regimen selected and customized to the individual patient, and then supported during the initial few months of therapy. It is recognized that general strategies to manage drug-related AEs effectively are critical in supporting patient adherence with all antiretroviral medications, which are outlined in Table 1. This paper highlights the important general considerations and then provides recommendations that are more specific to the neuropsychiatric symptoms associated with efavirenz. The recommendations are organized where applicable as: before initiation of therapy; initial period of therapy; and for persistent symptoms despite appropriate management. The evidence on which the consensus recommendations are based is also outlined.

\section{GENERAL MANAGEMENT STRATEGIES FOR EFAVIRENZ THERAPY AND ASSOCIATED AEs}

Major depression occurs frequently in patients with HIV/AIDS, with estimated prevalence rates of $22 \%$ to $45 \%$ (59). Major depression is often undiagnosed and undertreated. A short screening for depression using a few focused questions should be routinely considered when planning to initiate antiretroviral agents that may potentially exacerbate depression. Screening is most effective when combined with a patient-support follow-up program. Two simple questions 
have been found useful in screening patients and have, in primary care practices, yielded a case-finding sensitivity of $96 \%$ and a specificity of $57 \%$ in detecting depression (10). These questions, which focus on mood and the capacity to experience pleasure, are: "During the past month, have you often been bothered by feeling down, depressed or feelings of hopelessness?" and "During the past month, have you often been bothered by having little interest or pleasure in doing things?" Patients indicating yes to either question should be further assessed with a clinical interview. Alternatively, a short, self-administered questionnaire such as the Beck Depression Inventory (BDI) may be used for screening. Scores of 14 or greater on the BDI should prompt further assessment for depression.

Because CNS symptoms may appear within the first or second day of therapy, efavirenz should ideally be initiated during a period that would not require the patient's focused attention or energy, and during which the patient has ready access to support. The optimal timing for efavirenz initiation must be determined with the patient, recognizing the possible AEs and the strategies used to manage these potential AEs.

Poor adherence may occur when medications produce AEs in persons who were previously well (11). Initial and ongoing patient education and support are critical in assisting patients in the management of any AEs. Dedicated staff and programs have been found to improve adherence and patient outcomes (12-15). In a study involving 116 patients initiating HAART, patients were randomized to receive either routine care or intensive education and sustained support interventions (14). It was found that while both groups initially had high adherence levels, the control patients demonstrated a decrease in adherence over time such that the difference in adherence at 48 weeks was significant $-94 \%$ in the intervention group and $69 \%$ in the control group $(\mathrm{P}=0.008)$. Intervention patients received intensive explanation regarding the treatment and relevance of adherence before the initiation of HAART. Any potential barrier to adherence was identified, and a plan was established with the patient's input. Patients were also taught how to minimize medication-related AEs through changes in their daily routine. Finally, a phone number was provided in case additional questions or problems arose between interviews. During the follow-up visits, adherence was verbally reinforced and strategies were developed to solve the problems that had appeared up to that point. In addition to better adherence, the intervention patients had better virological control after one year. Therefore, intensive education before initiation of therapy, ongoing patient support and close monitoring are essential elements that affect a patient's ability to achieve the maximum benefit from therapy.

Despite appropriate management and ongoing support, some AEs may persist and pose a barrier to patient adherence for a small percentage of patients. After a period of observation and attempts at symptom control, a discussion should take place with the patient regarding future strategies such as other coping strategies or alternate antiretroviral options.

\section{Before therapy initiation:}

- Evaluate the patient's psychological and psychiatric status.

- Screen for significant psychiatric illnesses and psychological distress.

- Stabilize and treat any conditions identified using standard psychiatric interventions.

- If the patient has a history of psychiatric illnesses, establish or re-establish support systems and mental health contact.

- Provide patient education and counselling.

- Ensure the patient is ready to start HAART.

- Provide counselling and ensure patient understands the common potential AEs of drug therapy including the nature, frequency, severity and duration.

- Provide written information.

- Always involve family and friends (if available and with patient consent).

- Provide counselling about the long term or indefinite period for HAART maintenance.

- Consider the patient's social situation and evaluate the appropriate timing of therapy initiation.

- Avoid initiation during high stress or critical periods of patient's life.

- Initiate therapy during a period in the patient's life when the emergence of AEs will have the least negative consequences.

Initial period of efavirenz therapy:

- Provide close patient follow-up or monitoring.

- Begin an active program to contact patient within a few days of initiating efavirenz therapy. (A flow chart or follow-up guide may be used to remind staff.)

- Ensure that patient support is available.

- Provide assurance that most AEs should resolve within a few weeks and monitor the severity of any AEs experienced.

- Ensure that, if possible, the patient has personal support (friends and family) for the initial weeks of therapy.

- Provide patient with a phone number to call if experiencing problems and have a plan in place for accessing crisis services if needed.

\section{Persistent symptoms despite appropriate management:}

- Continue patient support and monitoring.

- Determine any other causes or exacerbating factors for the symptoms experienced. 
TABLE 2

Sleep hygiene measures

Strategies

Do:

- Maintain regular sleep/wake habits (ie, wake up at same time and go to bed at same time everyday).

- Exercise in the morning.

- Sleep only enough to be refreshed.

- Maintain a cool, dark sleep area.

- Keep the bed for sleeping. If you cannot sleep after 20 min, get out of the bed for a period of 10 or 15 min rather than staying in bed tossing and turning.

- Relaxation exercises.
Avoid:

- Exercise in evenings.

- Going to bed with a full stomach.

- Caffeine, nicotine and alcohol in evenings.

- Noise and extremes of temperature in bedroom.

- Staying in bed for prolonged periods if the patient cannot sleep.

- Don't let your mind associate the bed with activities of wakefulness.

- Reading and watching television in bed.

Data from references 20, 21, 32

- Evaluate the severity of symptoms and the impact on patient's quality of life.

- Treat emergent neuropsychiatric syndromes with standard psychiatric interventions.

- If symptoms persist despite psychiatric intervention, discontinuing efavirenz may be necessary.

\section{MANAGEMENT RECOMMENDATIONS FOR SPECIFIC CNS SYMPTOMS ASSOCIATED WITH EFAVIRENZ}

Agitation: Agitation is one of the CNS symptoms that may be experienced by patients on efavirenz. However, agitation may also be due to other underlying etiologies such as major depression, anxiety over new stressors in a patient's life, or secondary to pharmacological agents such as caffeine, prednisone, antidepressants with activating AEs and substance abuse (16-18).

Once other causes of agitation have been ruled out, ongoing support counselling to encourage continuation with therapy (because this symptom will likely resolve) is essential. Stress-relieving activities, including exercise such as yoga or relaxation therapies, may be suggested. Empirical pharmacological treatment carefully selected to avoid drug interactions may also be instituted (19). Benzodiazepines or neuroleptic agents (haloperidol, clozapine, olanzapine) may be effective in the management of agitation and aggression in the nonHIV psychiatric patient population $(16,18)$. Because anxiolytics are potentially addictive, such drugs should be only for acute agitation and their use should be limited to no more than four to eight weeks. Although antipsychotic medications are not indicated for the management of agitation, some patients with nonpsychotic disorders presenting with agitation may respond to a low dose antipsychotic such as olanzapine 2.5 to $5 \mathrm{mg}$ at bedtime for the acute management of severe agitation pending a more formal psychiatric evaluation.

\section{Initial period of efavirenz therapy:}

- Nonpharmacological management

- Evaluate for other potential causes, including psychiatric, and medical and substance use, and manage accordingly.

- Minimize stimulant intake, including caffeine, prescription or over the counter medications, or illegal substances.

- Suggest stress-relieving activities (eg, exercise, meditation, relaxation techniques).

\section{- Pharmacological management}

- Anxiolytics for mild agitation such as lorazepam 0.5 to $2 \mathrm{mg}$ every $4 \mathrm{~h}$ as needed or clonazepam 0.5 to $1 \mathrm{mg}$ every $4 \mathrm{~h}$ as needed. Daily doses should not exceed $4 \mathrm{mg}$, and use should be limited to four to eight weeks' duration.

- Consider low dose neuroleptic for more severe cases such as olanzapine (Zyprexa, Eli Lilly Canada Inc, Canada) 2.5 to $5 \mathrm{mg}$ at bedtime pending a more formal psychiatric evaluation.

\section{Persistent symptoms on efavirenz therapy:}

- Provide reassurance and support.

- Continue to evaluate for other potential causes such as depression and treat as appropriate.

- Refer for psychiatric evaluation. 
Sleep disturbances: Insomnia and sleep disturbance are widespread and often underdiagnosed in HIV-positive patients. In one study, $73 \%$ of the HIV patients were found to have insomnia, yet only $45 \%$ of the patient charts contained any documentation of insomnia. Insomnia may be caused by many factors: psychiatric (depression, anxiety); medical (sleep apnea, pulmonary disease or HIV/AIDS disease); and pharmacological (caffeine, alcohol, secondary to psychotropics including antidepressants) (20). Causes of insomnia should be explored and treated appropriately.

Nonpharmacological behavioural strategies can be used to manage sleep disturbances $(20,21)$. Sleep hygiene measures (Table 2) aim to remove possible deterrents to sleep, to apply structure to sleep patterns and to prevent association of the bed with activities of wakefulness. Additional interventions such as progressive muscle relaxation, biofeedback and cognitive behavioural therapy may be of benefit. Anecdotally, adjusting the administration times of efavirenz to earlier in the evening or during the day has also provided symptom relief.

Pharmacological therapy may include the use of hypnotics including short-acting benzodiazepines (ie, lorazepam or oxazepam) or zopiclone. These agents may be particularly useful in patients who have trouble falling asleep. For patients with middle insomnia (trouble maintaining sleep), low dose trazodone, an effective hypnotic (at dose range of 25 to $150 \mathrm{mg}$ at bedtime), may be used. Longacting benzodiazepines have active metabolites that produce more AEs, including cognitive side effects and have higher potential for drug interaction in patients with HIV/AIDS (17). In addition, concurrent administration of protease inhibitors with benzodiazepines that are substrates of CYP3A4 (eg, diazepam) may result in an increased benzodiazepine concentration and additional AEs $(22,23)$. Patients with terminal insomnia (early morning awakening) should be treated as having presumed depression. Early morning awakening is a classic sign of major depression, and patients presenting with it should be evaluated for major depression. Often sleep disturbance and major depression both require treatment with the use of an antidepressant and hypnotic. Balancing the need for sleep and the potential toxicities associated with long term hypnotic usage is challenging. In general, hypnotics should be used at as low a dose for as limited duration as possible. Prescriptions should be monitored and small amounts prescribed to mitigate against nonjudicious usage pattern. Failure to manage sleep symptoms should prompt a psychiatric consultation or evaluation by a sleep specialist.

\section{Initial period of efavirenz therapy:}

\section{- Nonpharmacological management}

- Evaluate for underlying cause of insomnia and treat accordingly.

- Conduct a sleep hygiene evaluation (Table 2).

- Adjust efavirenz dosage administration time earlier (eg, during the day).

\section{- Pharmacological management}

- For early insomnia (trouble falling asleep), use short-acting benzodiazepine such as lorazepam 1 to $2 \mathrm{mg}$ at bedtime as needed and consider giving a small prescription (ie, no more than two weeks) at the time of efavirenz initiation.

- For middle insomnia (trouble maintaining sleep), a longer-acting hypnotic may be required. Low dose trazodone (Desyrel, Bristol Myers-Squibb, Canada), 25 to $100 \mathrm{mg}$ at bedtime, is recommended.

- For terminal insomnia (early morning awakening), the patient should be assessed for depression and treated as appropriate. An antidepressant with hypnotic effect such as low dose trazodone, 25 to $100 \mathrm{mg}$ at bedtime, is recommended.

\section{Persistent symptoms on efavirenz therapy:}

- Continue to evaluate for other potential causes such as depression and treat as appropriate.

Dreams: Many patients taking efavirenz often report vivid dreams. Dream content can vary widely, from pleasant to disturbing in nature. Some patients will complain of dreams so vivid that they do not get a restful sleep. No studies have been undertaken on the management of disturbing dreams in either the HIV or general patient population. Patient education before initiating therapy and ongoing supportive counselling are critical to successful therapy.

Some interventions that have anecdotally provided relief are changing the efavirenz to an earlier administration time such as several hours before bedtime; splitting the dosing of efavirenz to twice daily; and performing mental exercises such as focused thoughts, visualization or using soft music to achieve a peaceful frame of mind before sleeping. Additionally, hypnotics such as the short-acting benzodiazepines may also be tried.

\section{Initial period of efavirenz therapy:}

- Nonpharmacological management

- Consider exercises such as focused thoughts, visualization and the use of soft music, etc, before sleeping.

\section{- Pharmacological management}

- Consider efavirenz dosing administration adjustment (earlier in the evening or during the day, or twice daily administration with a larger dose at bedtime). Note, however, that the impact of split-dosing on antiretroviral efficacy is not clear.

- Consider a trial of short-acting benzodiazepine such as lorazepam 1 to $2 \mathrm{mg}$ at bedtime as needed.

Dizziness: Dizziness is often described as light-headedness and a feeling of unsteadiness (unsure of where to put one's feet). Patients can experience dizziness at any time of the 
day. Patient supportive counselling remains the mainstay of the management of dizziness. However, one should rule out other causes of dizziness such as concurrent psychoactive drugs.

Anecdotal reports of adjusting the timing of efavirenz administration to minimize symptoms have resulted in symptom improvement. A patient experiencing dizziness, mostly in early morning, may consider moving dosing from bedtime to suppertime or consider twice-daily dosing with a smaller dose at bedtime. Patients with severe dizziness and at risk of falls should be reassessed regarding therapeutic options.

\section{Initial period of efavirenz therapy:}

\section{- Nonpharmacological management}

- Reconsider efavirenz dose schedule depending on when the patient experiences dizziness.

- Rule out concurrent psychoactive drugs, including illicit drugs.

- Counsel patients about avoiding activities requiring concentration (eg, driving a car).

- Counsel patients on home environment safety. Identify and remove any obstacles that may cause accidental falls (eg, clothing on floor).

Impaired concentration: Impaired concentration is one of the efavirenz-related CNS symptoms that usually resolves within a few weeks (3). In addition to reassurance and supportive counselling, the physician should assess the patient for underlying causes of impaired concentration. Other causes of impaired concentration include insomnia, depression, cognitive disorders associated with HIV/AIDS and substancerelated disorders $(10,24,25)$.

Anecdotally, adjusting the dosing administration of efavirenz (according to the time during the day when impaired concentration occurs or is most severe) has provided symptom relief. Splitting the dose to a twice-daily administration has also been tried; however, the impact of split-dosing on antiretroviral efficacy is unclear. In addition, coping strategies should be discussed with patients with persistent impaired concentration. Neurorehabilitation coping strategies using prompting and compensatory techniques may be useful, and include the use of a memory book, Post-it Notes, a computer or paging devices to reduce the patient's reliance on memory.

\section{Initial period of efavirenz therapy:}

\section{- Nonpharmacological management}

- Consider efavirenz dosing administration adjustment (depending on when symptom is most severe). A trial of twice-daily administration may be considered. Note, however, that the impact of split-dosing on antiretroviral efficacy is not clear.

\section{Persistent symptoms on efavirenz therapy:}

- Employ memory aids as used in neurorehabilitation (eg, memory book, Post-it Notes, etc).

- Continue to evaluate for other potential causes such as depression and treat as appropriate.

Depression: Depressive symptoms (anxiety, agitation, insomnia, etc) are common in patients with HIV/AIDS and may be due to many factors including disposition to major depression, psychosocial stressors, progression of HIV/AIDS, psychoactive substance abuse or dependence, or a side effect of medications including efavirenz, zidovudine, interferon and prednisone (25).

Early identification of depression and treatment is important. Screening questions with appropriate follow-up (outlined earlier) should be incorporated in the routine monitoring by clinic staff. The diagnosis of major depression is made by identifying the classic symptoms of major depression as outlined in the Diagnostic and Statistical Manual of Mental Disorders, Fourth edition (17). Major depression in patients with HIV/AIDS is managed using standard psychiatric interventions, and these are useful regardless of the presumed underlying cause of the major depression.

In patients with mild to moderate depressive symptomatology, psychotherapy alone may help remit symptoms. In patients with moderate to severe symptoms, psychopharmacological intervention alone or in combination with psychotherapy is necessary. Antidepressants such as selective serotonin reuptake inhibitors (SSRIs) and tricyclic antidepressants have demonstrated similar efficacy in HIV patients as in the general population (26-29). SSRIs are better tolerated and have emerged as first-line interventions (30).

Antidepressant treatment should be initiated at low dose and titrated slowly to standard therapeutic doses (17). Patients should be initiated on half of the recommended starting dose and titrated to the starting dose after seven to 10 days if the drug is well tolerated. The patient's clinical response should be evaluated regularly, with special attention to patient safety and drug tolerability, and the dosage should be adjusted accordingly (31). In patients who do not experience symptom improvement after four to six weeks of antidepressant treatment, a low dose neuroleptic (eg, olanzapine 2.5 to $5 \mathrm{mg}$ at bedtime) may be tried concurrently because symptoms of depression and psychosis often overlap.

Response generally begins to occur after three weeks with significant improvement by weeks 4 to 6 . A lack of response to one agent at week 6 should prompt a dosage increase, if possible, switch to a second agent or use of a standard augmentation strategy. Psychiatric evaluation should be sought, particularly in patients that do not respond to standard interventions. After the remission of depression is achieved, it is necessary to continue therapy for at least nine to 12 months (10) to consolidate the effect and minimize relapse. 
TABLE 3

Summary of consensus recommendations: General management strategies for treating patients prescribed efavirenz

All HIV patients should be routinely screened for depression and any psychiatric conditions.

\section{Before efavirenz initiation:}

- Stablize any current psychiatric conditions or symptoms.

- Establish or re-establish support systems and mental health contact if the patient has a history of psychiatric illnesses.

- Establish patient readiness for antiretroviral therapy and that the timing of therapy initiation is appropriate.

- Ensure that the patient understands the importance of adherence and understands the long term and indefinite medication therapy that is required.

- Provide information and ensure that the patient understands the potential adverse effects and management approaches.

Initial period of efavirenz therapy:

- Ensure that patient support is available.

- Provide close patient follow-up or monitoring of treatment-emergent adverse effects.

- For any adverse effect, patient education and support counselling are critical.

- If the patient experiences any of the following, refer to the appropriate sections for further management strategies (see Table 4):

$\begin{array}{ll}\square \text { Agitation } & \square \text { Dizziness } \\ \square \text { Sleep disturbances } & \square \text { Impaired concentration } \\ \square \text { Dreams } & \square \text { Depression }\end{array}$

Persistent symptoms despite appropriate management

- Continue patient support and monitoring.

- Determine whether there are any other causes or exacerbating factors for the symptoms experienced.

- Evaluate the severity of the symptoms and their impact on quality of life.

- Discuss future options with the patient, including drug discontinuation if standard treatments fail to resolve emergent adverse effects.

\section{Before initiation and during the initial period of efavirenz therapy:}

\section{- Nonpharmacological management}

- Early psychiatric treatment: Re-establish patient contact with psychiatric care if a patient had a prior history, and for patients with a new episode, initiate a psychiatric consultation. Provide psychosocial support and structured therapy.

- Pay special attention to issues of patient safety.

- Ensure patient is aware of and has access to crisis support services.

- Provide close patient follow-up or monitoring: Ensure contact by clinic staff using a follow-up guide with focused screening questions and perform routine screening at clinic visits.

\section{- Pharmacological management}

- Prescribe antidepressant therapy for patients with moderate to severe symptoms. Initiate at a low dose and titrate slowly.

\section{Persistent symptoms despite appropriate management:}

- Refer to a psychiatrist.

- If symptoms do not respond to standard psychiatric intervention, consider a change in antiretroviral combination.

\section{CONCLUSIONS}

One of the factors that may adversely affect patient adherence and potentially lead to early therapy interruptions are drug AEs. Strategies that minimize or improve the tolerance of AEs are believed to improved adherence and patient outcomes.

Approximately $50 \%$ of the patients initiated on efavirenz experience CNS symptoms. We have outlined general management recommendations (Tables 3,4), which apply to any AE related to efavirenz initiation, as well as specific management strategies for CNS symptoms such as agitation, sleep disturbances, dreams, dizziness, impaired concentration and depression. The guidelines include nonpharmacological and pharmacological interventions for the management of symptoms during the initial period of ther- 
TABLE 4

Symptom-specific management strategies for HIV-positive patients taking efavirenz

\begin{tabular}{|c|c|c|c|}
\hline $\begin{array}{l}\text { Specific } \\
\text { symptoms }\end{array}$ & $\begin{array}{ll}\text { Nonpharmacological } & \text { Inial period of } \mathrm{e}\end{array}$ & $\begin{array}{l}\text { favirenz therapy } \\
\text { Pharmacological }\end{array}$ & Persistent symptoms \\
\hline Agitation & $\begin{array}{l}\text { - Evaluate for other potential causes, } \\
\text { including psychiatric, medical and } \\
\text { substance use, and manage accordingly. } \\
\text { - Minimize stimulant intake including } \\
\text { caffeine, prescription or } \\
\text { over the counter medications, or } \\
\text { illegal substances. } \\
\text { - Suggest stress-relieving activities } \\
\text { (eg, exercise, meditation, } \\
\text { relaxation techniques). }\end{array}$ & $\begin{array}{l}\text { - Anxiolytics for mild agitation } \\
\text { such as lorazepam } 0.5 \text { to } 2 \mathrm{mg} \\
\text { every } 4 \mathrm{~h} \text { as needed or } \\
\text { clonazepam } 0.5 \text { to } 2 \mathrm{mg} \\
0.5 \text { to } 1 \mathrm{mg} \text { every } 4 \mathrm{~h} \text { as needed. } \\
\text { Daily doses should not exceed } \\
4 \mathrm{mg} \text {, and use should be limited } \\
\text { to } 4 \text { to } 8 \text { weeks. } \\
\text { - Consider low dose neuroleptic } \\
\text { for more severe cases such as } \\
\text { olanzapine (Zyprexa, Eli Lilly Canada Inc, } \\
\text { Canada) } 2.5 \text { to } 5 \text { mg HS pending more } \\
\text { formal psychiatric evaluation. }\end{array}$ & $\begin{array}{l}\text { - Reassurance and support. } \\
\text { - Continue to evaluate for other } \\
\text { causes such as depression } \\
\text { and treat as appropriate. } \\
\text { - Refer for psychiatric evaluation. }\end{array}$ \\
\hline Dreams & $\begin{array}{l}\text { - Adjust efavirenz administration timing } \\
\text { (eg, give during the day). } \\
\text { - Consider exercises such as } \\
\text { focused thoughts, visualization } \\
\text { and soft music before sleep. }\end{array}$ & $\begin{array}{l}\text { - Institute a trial of short-acting } \\
\text { benzodiazepine for mild agitation } \\
\text { such as lorazepam } 1 \text { to } 2 \mathrm{mg} \\
\text { every } 6 \mathrm{~h} \text { as needed. }\end{array}$ & \\
\hline $\begin{array}{l}\text { Impaired } \\
\text { concentration }\end{array}$ & $\begin{array}{l}\text { - Adjust efavirenz administration timing } \\
\text { depending on when impaired } \\
\text { concentration occurs or is most severe. }\end{array}$ & & $\begin{array}{l}\text { - Memory aids as used in } \\
\text { neurorehabilitation } \\
\text { (eg, memory book, Post-it } \\
\text { Notes). } \\
\text { - Continue to evaluate for } \\
\text { other causes such as depression } \\
\text { and treat as appropriate. }\end{array}$ \\
\hline Depression & $\begin{array}{l}\text { - Establish or re-establish patient contact } \\
\text { with psychiatric care. } \\
\text { - Provide psychotherapy and psychosocial } \\
\text { - } \text { support for mild to moderate symptoms. } \\
\text { Pay special attention to issues of patient } \\
\text { safety. } \\
\text { - Ensure patient access to crisis support } \\
\text { services. } \\
\text { - Provide close patient follow-up or } \\
\text { monitoring. }\end{array}$ & $\begin{array}{l}\text { - Use an antidepressant (SSRI is } \\
\text { preferred) alone or in combination } \\
\text { with psychotherapy for moderate } \\
\text { to severe symptoms. }\end{array}$ & $\begin{array}{l}\text { - Refer to psychiatry. } \\
\text { - Consider low dose neuroleptic } \\
\text { such as olanzapine } \\
2.5 \text { to } 5 \mathrm{mg} \mathrm{HS} \\
\text { after } 4 \text { to } 5 \text { weeks } \\
\text { of antidepressant therapy. }\end{array}$ \\
\hline
\end{tabular}

HS At bedtime; SSRI Selective serotonin reuptake inhibitors 
apy as well as for persistent symptoms. We hope that these guidelines will be of value to clinicians in customizing a regimen for the individual patient, providing support during the initial period of therapy and managing the therapyrelated $\mathrm{AE}$ so as to maximize the benefit of long term viral suppression that can be achieved with efavirenz therapy.

\section{APPENDIX A}

The Efavirenz Consensus Working Group comprises: Dr Jean-Guy Baril, Clinique Médicale du Quartier Latin, Montreal, Quebec; Christine Hughes, BScPharm PharmD, Faculty of Pharmacy \& Pharmaceutical Sciences, University of Alberta, Capital Health Region, Edmonton, Alberta; Drs Roger Leblanc, Department of Internal Medicine, McGill University, Immunodeficiency Clinic, Montreal Chest Hospital, Montreal, Quebec; Eric Lefebvre, Clinique l'Actuel, Montreal, Quebec; Stuart J Rosser, HIV Program, University of Manitoba, Winnipeg, Manitoba; Irving Salit, Department of Medicine, University of Toronto, Immunodeficiency Clinic, University Health Network, Toronto, Ontario; Stephen D Shafran, Department of Medicine, Division of Infectious Diseases, University of Alberta, Edmonton, Alberta; Graham Smith, Immunodeficiency Service, Royal Victoria Hospital, Montreal, Quebec; Rachel Therrien BPharm DPH CHUM Pavillon Hotel Dieu, Montreal, Quebec; Dr Dominique Tessier, CHUM Pavillon St-Luc Montreal, Quebec; Alice Tseng, BscPhm PharmD, Faculty of Pharmacy, University of Toronto, Toronto General Hospital, Toronto, Ontario; Laura Park Wyllie, BScPhm PharmD, Faculty of Pharmacy, University of Toronto, Department of Family \& Community Medicine, University of Toronto, St Michael's Hospital, Toronto, Ontario.

The Consensus Group Meeting was funded through an unrestricted grant from Dupont Pharma. Dr John Gill has received research grants from DuPont Pharma. Dr Anita Rachlis received honoraria for continuing medical education presentations, served as a consultant, and participated in research studies for DuPont Pharma, GlaxoSmithKline/ BioChem Pharma, Hoffmann-LaRoche Limited, Merck Frosst Canada \& Co, Abbott Laboratories Limited, Agouron Pharmaceuticals Canada Inc/Pfizer Canada Inc, and BristolMyers Squibb. Dr Sharon Walmsley has served on advisory board committees, and participated in clinical trials and speakers bureaus for Dupont Pharma. Dr Mark Halman is a principal investigtor on a study for GlaxoSmithKline.

\section{REFERENCES}

1. Panel on Clinical Practices for the Treatment of HIV Infection. Guidelines for the use of antiretroviral agents in HIV-infected adults and adolescents. Washington, DC: US Department of Health and Human Services and the Henry J Kaiser Family Foundation, 2001. (http://www.hivatis.org. Version current as of February 5, 2001.)

2. Carr A, Cooper DA. Adverse effects of antiretroviral therapy. Lancet 2000;356:1423-30.

3. Sustiva Product Monograph. Mississauga: DuPont Pharma, 2001.
4. Data on file, DuPont Pharma. Mississauga, Ontario.

5. Atkinson H, Grant I, Kennedy CJ, et al. Prevalence of psychiatric disorders, drug use, and medical status in injection drug users with HIV disease. Am J Addict 1996;246-58.

6. Kelly B, Raphael B, Judd F, et al. Psychiatric disorder in HIV infection. Aust N Z J Psychiatry 1998;32:441-53.

7. Maj M, Janssen R, Starace F, et al. WHO neuropsychiatric AIDS study, cross-sectional phase I. Study design and psychiatric findings. Arch Gen Psychiatry 1994;51:39-49.

8. McDaniel JS, Fowlie E, Summerville MB, et al. An assessment of rates of psychiatric morbidity and functioning in HIV disease. Gen Hosp Psychiatry 1995;17:346-52.

9. Perkins DO, Stern RA, Golden RN, et al. Mood disorders in HIV infection: prevalence and risk factors in a nonepicenter of the AIDS epidemic. Am J Psychiatry 1994;151:233-6.

10. Whooley MA, Simon GE. Managing depression in medical outpatients. N Engl J Med 2000;324:1942-9.

11. Chesney MA, Morin M, Scherr L. Adherence to HIV combination therapy. Soc Sci Med 2000;50:1599-605.

12. Max B, Sherer B. Management of the adverse effects of antiretroviral therapy and medication adherence. Clin Infect Dis 2000;30(Suppl 2):S96-116.

13. Graham K, Beeler LH, Renae S, Sension MG. Interventions and patient outcomes from a pharmacist-based HIV medication and adherence referral clinic. XIIth World AIDS Conference. Geneva, June 28 to July 3, 1998. (Abst 323223)

14. Tuldra A, Fumaz CR, Ferrer MJ, et al. Prospective randomized two-arm controlled study to determine the efficacy of a specific intervention to improve long-term adherence to highly active antiretroviral therapy. J Acquir Immune Defic Syndr 2000;25:221-8.

15. Knobel H, Serrano C, Hernandez P, Pavesi M, Diez A. [Acceptance of, compliance with and tolerance to antiretroviral treatment in patients with human immunodeficiency virus infection]. An Med Interna 1997;14:445-9.

16. Buckley PF. The role of typical and atypical antipsychotic medications in the management of agitation and aggression. J Clin Psychiatry 1999;60(Suppl 10):52-60.

17. Fernandez F, Levy JK. Psychopharmacology in HIV spectrum disorders. Psychiatric Clin North Am 1994;17:135-48.

18. Schatzberg AF, DeBattista C. Phenomenology and treatment of agitation. J Clin Psychiatry 1999;60(Suppl 15):17-20.

19. Tseng AL, Foisy MM. Significant interactions with new antiretrovirals and psychotropic drugs. Ann Pharmacother 1999;33:461-73.

20. Holbroook AM, Crowther R, Lotter A, et al. The diagnosis and management of insomnia in clinical practice: a practical evidence-based approach. CMAJ 2000;162:216-20.

21. Thase ME. Treatment issues related to sleep and depression. J Clin Psychiatry 2000;61(Suppl 11):46-50.

22. Tseng AL, Foisy MM. Management of drug interactions in patients with HIV. Ann Pharmacother 1997;31:1040-58.

23. Pitscitelli SC, Flexner C, Minor JR, et al. Drug interactions in patients infected with human immunodeficiency virus. Clin Infect Dis 1996;23:685-93.

24. Rubinstein ML, Selwyn PA. High prevalence of insomnia in an outpatient population with HIV infection. J Acquir Immune Defic Syndr Hum Retrovirol 1998;19:260-5.

25. Penzak SR, Reddy YS, Grimsley SR. Depression in 
patients with HIV infection. Am J Health Syst Pharm 2000;57:376-86.

26. Elliot AJ, Russo J, Bergam K, et al. Antidepressant efficacy in HIV-seropositive outpatients with major depressive disorder: an open trial of nefazodone. J Clin Psychiatry 1999;60:226-31.

27. Ferrando SJ, Goldman JD, Charness WE. Selective serotonin reuptake inhibitor treatment of depression in symptomatic HIV infection and AIDS. Improvements in affective and somatic symptoms. Gen Hosp Psychiatry 1997;19:89-97.

28. Rabkin JG, Rabkin R, Harrison W, et al. Effect of imipramine on mood and enumerative measures of immune status in depressed patients with HIV illness. Am J Psychiatry 1994;151:516-23.
29. Zisook S, Peterkin J, Goggin KJ, et al. Treatment of major depression in HIV-seropositive men. J Clin Psychiatry 1998;59:217-24.

30. Cole JO, Bodkin JA. Antidepressant side effects. J Clin Psychiatry 1990;51(Suppl 1):21-6.

31. Depression Guideline Panel. Depression in Primary Care: Volume 2. Treatment of Major Depression. Clinical Practice Guideline, Number 5. AHCPR Publication No. 93-0551. Rockville: United States Department of Health and Human Services, Public Health Service, Agency for Health Care Policy and Research, 1993.

32. Sammiudin Z. Insomnia in HIV and its management: one clinician's perspective. Research Initiative Treatment Action 2000;6:5-9. 


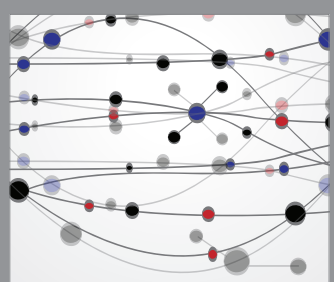

The Scientific World Journal
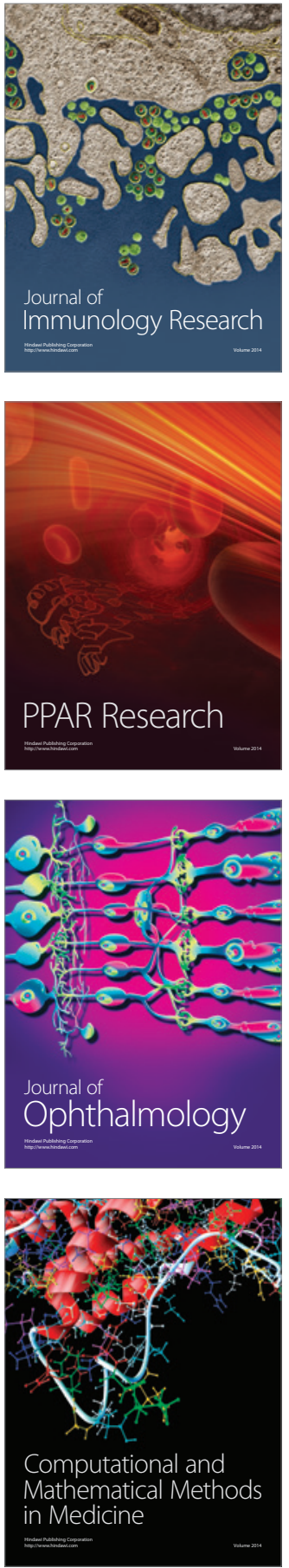

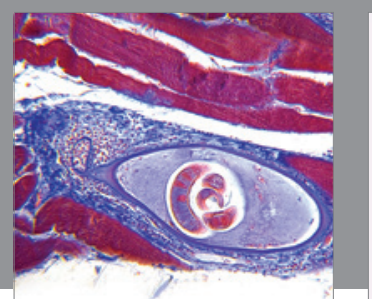

Gastroenterology Research and Practice

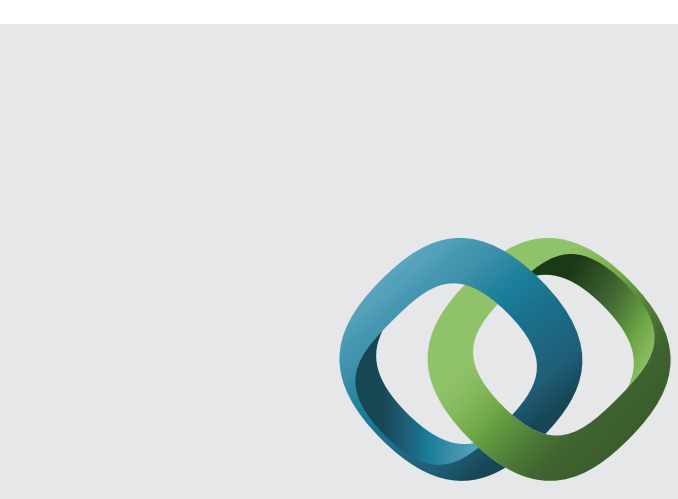

\section{Hindawi}

Submit your manuscripts at

http://www.hindawi.com
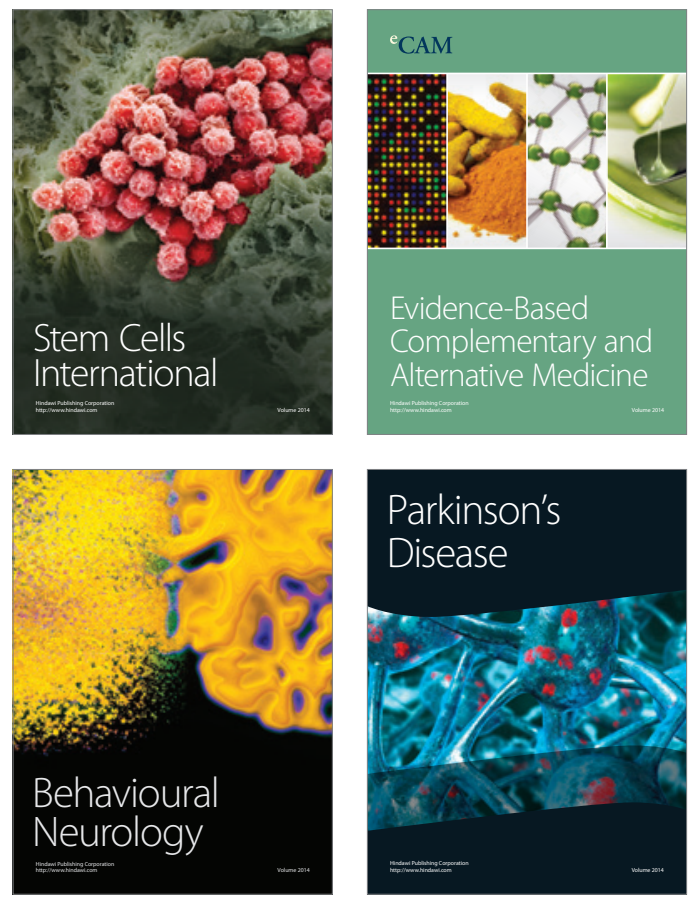
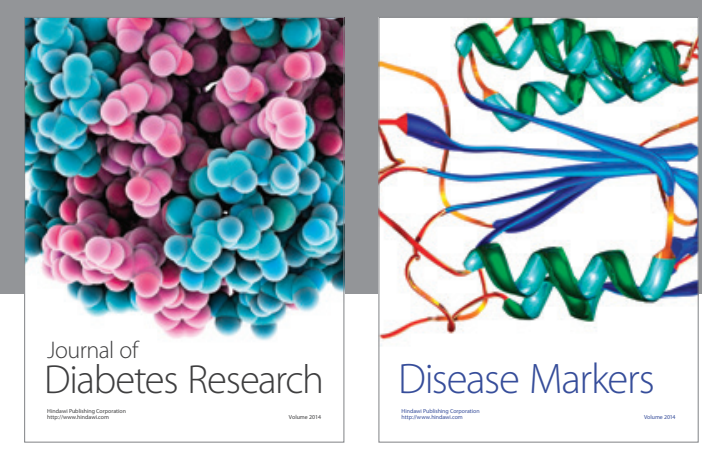

Disease Markers
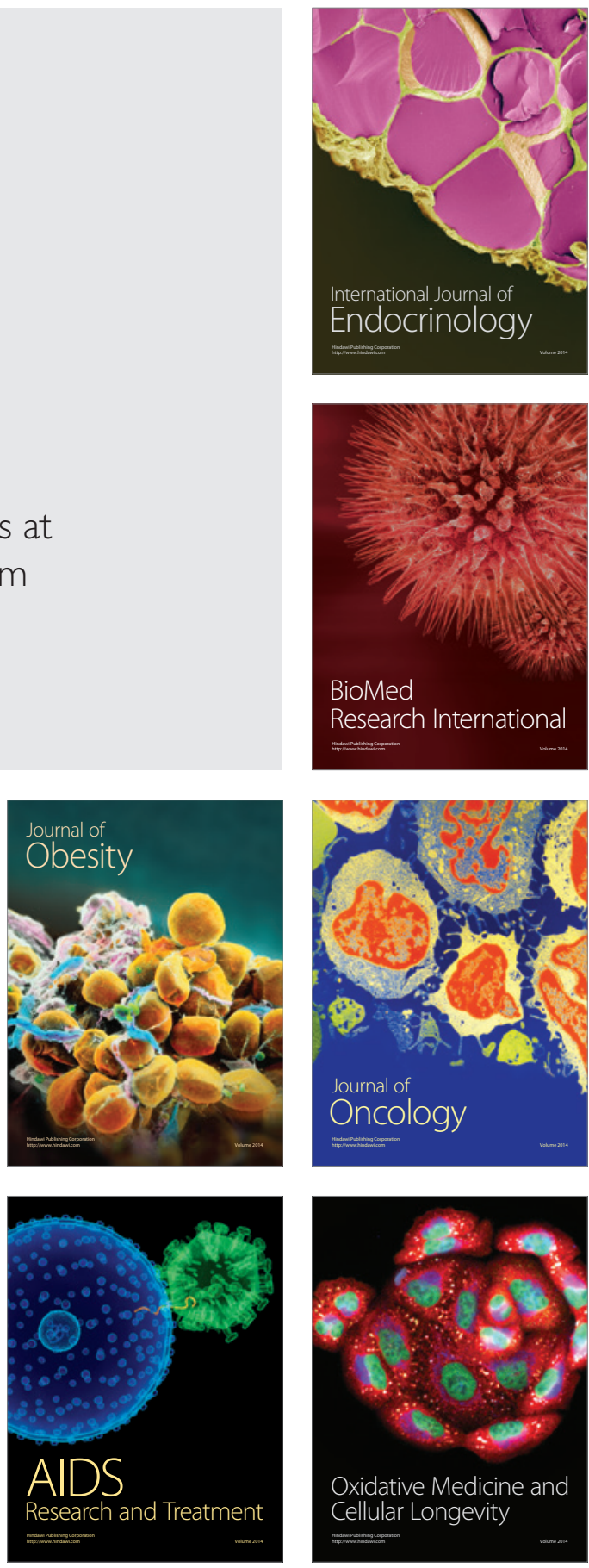